\title{
La fidelidad judía a las autoridades: un Memorial de cuando la pérdida turca de Buda en 1686
}

Fernando DÍAZ ESTEBAN

Universidad Complutense, Madrid

Por lo que tiene de ambiente de época y de rasgo de la vida de los judaizantes hispano-portugueses en Amsterdam, me ha parecido interesante comentar y reeditar el "Memorial» de fidelidad judía que supuestamente entregaron los judíos del gueto de Buda, tal y como lo publica Pizarro de Oliveros en Amsterdam.

\section{LOS ANTECEDENTES}

Antes de poner cerco a Viena en 1529 , el sultán turco Solimán II había dejado en 1526 una potente guarnición turca en la ciudad de Buda, so pretexto de ayudar al pretendiente al trono de Hungría, Juan Sophalia ${ }^{1}$, frente al rey Fernando de Bohemia, hermano del emperador Carlos v. Aunque se repelió el cerco turco de Viena, todos los intentos posteriores para recuperar Buda fracasaron y se llegó a un modus vivendi entre el rey y el pretendiente. Muerto Juan Sophalia en 1540, el intento cristiano de recuperar la ciudad hizo que se reforzara la posesión turca

${ }^{1}$ Oliver Fullana y Pizarro de Oliveros llaman respectivamente al pretendiente del trono de Hungría Zápolia y Sophalia. Mi amigo el profesor Jaime Vándor me indica amablemente que en húngaro el nombre correcto es Zápolya o Zápolyai. 
de Buda, pues el sultán, llegado en 1542 como aparente ayuda de los herederos, desterró a la viuda y al hijo de Juan Sophalia, pasando la ciudad a depender directamente de los turcos como una de sus mejores plazas fuertes.

La intranquilidad europea ante el peligro turco se despertó de nuevo con el segundo cerco de Viena en 1683, y aunque también fue repelido como el primero de 1529 , llevó a plantear la necesidad y conveniencia de liberar Buda y el resto de Hungría de sus ocupantes turcos. El triunfal asalto a Buda se llevó a cabo en 1686 y dio origen a una interesante estela literaria en castellano, que he estudiado recientemente ${ }^{2}$. A juzgar por esa producción literaria, la liberación cristiana de Buda llegó a suscitar esperanzas de una nueva cruzada que liberara Constantinopla e incluso Jerusalén y Tierra Santa del poder de los mahometanos.

Los judaizantes hispano-portugueses establecidos en los Países Bajos, como el resto de los españoles que allí vivían ocasionalmente, tuvieron noticias completas y rápidas del desarrollo de los acontecimientos, tanto del cerco de Viena de 1683 como del asalto a Buda de 1686. En el caso de los judaizantes, se juntaban dos razones para que estuvieran especialmente interesados en aquellos acontecimientos: una, la existencia en Buda de una famosa judería, el gueto de Buda; la otra, el que algunos de ellos eran oficiales de las tropas españolas de Flandes, los famosos Tercios, o estaban relacionados económicamente con los intereses españoles. Éste era el caso de don Manuel de Belmonte, alias de Isaac Núñez de Belmonte, Residente de su Majestad Católica en los Países Bajos. Había recibido el nombramiento de Agente del rey de España en 1671 y de Residente en 1679. En 1680 el emperador Leopoldo I le había nombrado Conde Palatino, nombramiento que no publicó cuando se enteró de que era judío, y en 1693 Carlos II le otorgó el título de Barón. Había nacido en Castilla hacia 1635 y murió en Amsterdam en 1705. Su misión en la ciudad holandesa era recibir y despachar informaciones políticas y comerciales ${ }^{3}$.

\footnotetext{
${ }^{2}$ Véase mi artículo "La retirada turca de Buda-Pest en 1686 vista por el lado europeo", Boletín de la Asociación Española de Orientalistas (en prensa).

${ }^{3}$ Puede verse una breve semblanza de Belmonte en R. Ayoun y H. Vidal SépHIHA, Sepharades d hier et d'aujourd hui: 70 portraits (Paris 1992) págs. 178179.
} 


\section{La obra de Pizarro de Oliveros}

Unos ocho meses después de finalizar el asalto a Buda, que terminó el 2 de septiembre de 1686, Antonio Pizarro de Oliveros publica un libro con el relato detallado de la preparación y el desarrollo del largo asalto a Buda, que había empezado en junio con una gran movilización de recursos bélicos y que conllevó grandes pérdidas de hombres y materiales, tanto por parte turca como por parte cristiana.

El largo título del libro es un ejemplo de los gustos de la época:

CESAREO CARRO TRIUMPHAL / En que Gloriosamente campean / por el Orbe las invencibles Armas / del Maximo Emperador Leopoldo / Primero de este nombre por la fe-/liz restauracion de la Real For-/taleza de Buda, conquistada / en 2 de Septe. de 1686. Relacion puntual, y verdadera que humilde consa-/gra, obsequioso ofrece, y reverente dedica al ardien/te Zelo, à la Virtud esclarecida, y à la Magnanimi-/dad generosa del Illustrissimo Señor Don Josseph / de Cossio Varreda del Consejo de Su Magestad, y/su Regente en el Supremo de Nabarra, Dignissimo / obispo de Salamanca \&ct. / Don Antonio Pizarro de Oliveros, Author de esta obra. / En AMSTERDAM / En Casa de Yacomo De Cordova / Año 1687.

Era costumbre admitida el que a veces alguien se hiciera cargo de la edición de un libro para dedicárselo a una tercera persona en prueba de afecto o respeto. Eso es lo que ocurrió con el libro de Pizarro de Oliveros, según explica en su «Dedicatoria" a don Josseph Cossío Varreda, fechada en Amsterdam el 15 de abril de 1687:

Don Josseph de Aldàs, y Aguirre, Natural de essa Imperial Ciudad de Pamplona, y Unico Español que reside en estas Provincias, haviendo leido en bosquejo la Relación que escrivì para sacar a luz este Libro ... me mandò lo consagrasse à los pies de Vuestra Illustrissima ...

En el "Prólogo al Lector", Pizarro explica cómo fue haciendo la obra:

Afortunado, Discreto, bien hablado, Amigo Lector, contigo, y no con los Maldizientes Murmuradores hasta de su propia Naturaleza enemigos hablo: Es muy natural en los Españoles el Amor à la Casa de Austria ... quando otras Naciones 
an dado diversos Panegiricos à la Imprenta, celebrando el Glorioso Triumpho de las Cesareas Armas en la dichosa restauracion de la Real Fortaleza de Buda, no es mucho quiera tambien una Pluma Española entrar a la parte de esta aclamacion luzida, siendo la mas interesada entre las Naciones todas. Atendiendo pues à esta razon, hize cuydado desde que se principió aquel Cerco de observar en las Relaciones que à esta Amstelodamica Ciudad venian, todo lo que en el [él], dia por dia, ìva sucediendo, y haviendo llegado el valor de los Combatientes al ultimo fin que deseavan, y mis escritos tambien con ellos al punto principal que queria, saco à luz aora con los materiales que me administraron aquellas valerosas diligencias, la fabrica de esta obra ...

Una segunda edición, con el mismo texto y tipografía, pero cambiando en el largo título Cesareo Carro Triumphal por Historia de los sucessos de Ungria, se publicó en 1690 también en Amsterdam y en Casa de Jacomo de Cordova. En la "Dedicatoria” de 1690 hay, amén del cambio de fecha, pequeñísimas variantes tipográficas. El papel es ligeramente más claro que en la edición de 1687 , pero es exactamente la misma obra ${ }^{4}$.

Pizarro de Oliveros se declara amigo del capitán de las tropas españolas en Flandes don Miguel de Barrios (como judaizante Daniel Leví de Barrios), del que hace un gran elogio como poeta: «Hizo Poeticamente, no solo de la referida Plaça, sino de todo el Reyno de la Ungria, una universal Descripcion mi Amigo el Capitan Don Miguel de Barrios", cuyas octavas van delante de toda la obra,

ô para darle en el [él] los Elogios que â alcançado su pluma en las Academias de España, y Flandes, ô para que con la dulçura, y erudicion de sus Versos te hagas capaz de las Regiones en que campea la Famosa Buda, ademas que quando logra este Insigne Sugeto, el primer assiento en el Parnaso, y el mas luzido Laurel entre las Musas, seria grosera ignorancia no darle la antelacion en mis Escriptos, a quien por las razones alegadas es Corona de preciosos engastes para el esplendor de esta Historia.

En las dos ediciones figuran los versos de Miguel de Barrios: un soneto laudatorio y una serie de octavas. El soneto a don

${ }^{4}$ Véase la descripción de ambas ediciones en Harm den BOER, "Spanish and Portuguese editions from the Northern Netherlands in Madrid and Lisbon Public collections", Studia Rosenthaliana 22 (1988) págs. 97-143 y 23 (1989) págs. 38-77 y 138-177: 23 pág. 155 núms. 291-292. 
Antonio Pizarro de Oliveros engarza el elogio al emperador Leopoldo "Germano Numa» con el del obispo de Salamanca "que en Pamplona grandeza obstenta suma", y el de Pizarro de Oliveros, pues Buda duda "si deve tanto al buelo de tu pluma" como a la espada que la liberó. En la serie de 35 octavas titulada Triumpho Cesareo En la Descripcion universal de Panonia, y Conquista de la Ciudad de Buda a 2. De Septiembre de 1686 Años Barrios hace una breve descripción geográfica de Hungría:

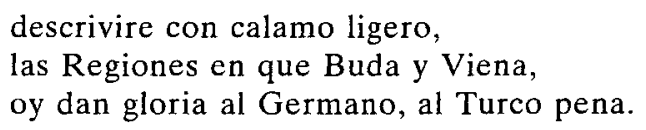

Pasa luego a atribuir orígenes mítico-bíblicos a los primeros pobladores de Austria y de Hungría, del modo fantasioso habitual en Barrios, recurso al que también acuden Pizarro de Oliveros y otros historiadores. Como en otro lugar he señalado ${ }^{5}$, Barrios tenía pasmosa facilidad para ensartar genealogías sin más apoyo que una lejana similitud fonética o una oscura referencia histórica.

Continúa Barrios describiendo la ocupación turca de Buda:

Buda de las Ciudades la mas bella,

brilla de Marte populosa estrella.

Fundola Keret del gran Scita hermano,

llamola Curta, y Offen oy se nombra ...

Offen, ô Curta, Corte interpretada.

Al hablar de la topografía de Buda, menciona el barrio judío:

En tres partes divisa se pregona, con la voz del Danubio cristalino, una, es la del Castillo que corona edificios de lustre peregrino;

la segunda es el Fuerte en que Belona, siempre el alfange desnudó ferino, y la tercera, del Judayco Gueto, todas tridente del marcial secreto,

y realza las dos murallas de la ciudad y su inexpugnabilidad, así como la existencia de fuentes termales curativas. Prácticamente, es la misma descripción que hace Pizarro de Oliveros (pág. 2):

\footnotetext{
s "Fanciful Biblical Etymologies", en Studies in Hebrew and Jewish Languages presented to Sh. Morag (Jerusalem 1996) págs. 3-14.
} 
Se descuella en un llano mas eminente predominando à todas las poblaciones de aquella Comarca la Fortaleza de Buda, plaça naturalmente fuerte, y que respecto de no ser superables sus defensas, convienen los Ingenieros en que no puede atacarse si no es dificultosamente por dos partes. Dividese esta Ciudad en el Barrio del Castillo, en la Ciudad, que llaman fuerte, y en el Gueto, ô separacion en que habitan los Judios.

La poesía de Miguel de Barrios termina con el paso de las tropas imperiales del Danubio por la puente de Gran ${ }^{6}$, que es el inicio del asalto definitivo relatado en el libro de Pizarro de Oliveros.

La noticia de la conquista de Buda ya la había recogido Barrios como "Prólogo" de la recopilación de casi todas sus poesías, que publicó con el título de Bello Monte de Helicona (Bruselas $=$ Amsterdam 1686) ${ }^{7}$, el mismo año del asalto. Se trata de un romance En ocasion que los imperiales conquistaron à Buda Corte de Hungria de 24 versos, en los que se hace el elogio del Duque de Lorena y del duque de Baviera, que mandaban los dos ejércitos atacantes, las dos «alas» del águila imperial, para terminar con el del Conde Palatino Manuel de Belmonte: "Entre este campo de elogios, / el Bello monte amanece, / que dedicado a Belmonte / flores en sus plantas tiene»; son varias más las poesías dedicadas a Belmonte por Barrios. Y asimismo recoge el soneto "Aplauso Harmonico Al Author, à su Mezenas, y al Heroe de la Obra. Del Capitan Don Miguel de Barrios", y las octavas que hizo para el libro de Pizarro de Oliveros, por entonces todavía en la imprenta.

En Bello Monte de Helicona Barrios incluye (pág. 25) además un soneto en elogio de don José de Aldás, el pamplonica que contribuyó a la publicación de la obra de Pizarro de Oliveros:

Elogio Lyrico Al Muy Noble Señor Don Joseph de Aldaz y Aguirre y Narvaez, natural de la Imperial Ciudad de Pamplona, y de las mejores casas Solariegas de Navarra, Cavallero Hidalgo de todos quatro costados, y siendo de poca edad fue uno de los Regidores de Pamplona. Sus Armas son Flores de Lis, Vandas coloradas, Campo Azul, y de oro, con una Haspa, y un Chopo, con una Loba parida al pie, y unos panales;

\footnotetext{
${ }^{6}$ Debo también al profesor J. Vándor la precisión de que la ciudad de Gran se llama actualmente Esztergom, siendo Strigonium en latín medieval y Solva en tiempos romanos.

7 Vid. Boer «Spanish and Portuguese editions» 23 pág. 48 núm. 120.
} 
a continuación (pág. 26) otro soneto a Cossio Varreda:

Honorifica Competencia De las inclitas Ciudades de Pamplona, y Salamanca, una fundada de Haran hijo de Terah, y otra, de Salmá hijo de Ragau. En los harmonicos aplausos del Ilustrissimo Señor Don Joseph de Cossio Varreda del Consejo de su Magestad, y su Regente en el Supremo de Navarra, dignissimo Obispo de Salamanca.

El hecho de que Pizarro de Oliveros fuera amigo de Miguel de Barrios permite suponer que también tuviera alguna relación con D. Manuel de Belmonte y es posible que uno y otro le influyeran para que incluyera la copia del "Memorial» presentado a los nuevos dueños de la ciudad por los judíos del gueto, memorial que contenía un alegato de fidelidad judía a los Príncipes legítimos.

M. Kayserling ${ }^{8}$ al hablar de la obra de Pizarro de Oliveros dice:

Dans cette description on lit p. 110: "Sobre lo sucedido en este Assalto, tubo aviso del mismo Cerco el Señor D. Manuel de Belmonte, Conde Palatino del Romano Imperio y Residente de su magestad catholica en estas Provincias Unidas de Holanda, y porque contiene la carta algunas particularidades mas de las que acabamos de referir, me parecio poner aquí la Copia de ella, aunque con alguna brevedad».

Kayserling no parece haber tenido delante la obra de Pizarro de Oliveros, sino que toma la noticia de S. Kohn ${ }^{9}$. No me ha sido posible consultar el trabajo de Kohn ni saber si éste tuvo delante el manuscrito original o alguna edición desconocida. Pero desde luego ni en la edición de Amsterdam de 1687 ni en la de 1690 se cita para nada a D. Manuel de Belmonte, aunque con toda probabilidad éste pondría parte de su archivo a disposición del historiador, pensando llevarle a la causa judía ${ }^{10}$. El texto de la página 110 citado por Kayserling lo que realmente dice es:

\footnotetext{
${ }^{8}$ En su Bibliotheca Española-Portugueza-Judaica: Dictionnaire Bibliographique Des Auteurs Juifs, de leurs ouvrages espagnols et portugais et des oeuvres sur et contre les Juifs et le Judaïsme, Avec un aperçu sur la littérature des Juifs espagnols et une collection des proverbes espagnols (Strasbourg 1890) pág. $25_{1}$ (s.v. Barrios, Miguel, págs. $16_{2}-26_{1}$ ).

9 Vid. Kayserling Bibliotheca pág. 25 nota 1, donde dice: «V. S. Kohn, Századok, XXI, p. 827 et suiv.".

${ }^{10}$ Harm den Boer parece considerar al propio Pizarro de Oliveros afín a los judíos, aunque sin explicar las razones; véase, por ejemplo, su libro La literatura sefardí de Amsterdam (Alcalá de Henares 1996) pág. 64.
} 
Sobre lo sucedido en este Assalto, algunos particulares affectos, y interessados en los buenos sucessos de lar [sic] armas Imperiales, tubieron avisso en esta Ciudad de Amsterdam, y porque todas las cartas que vinieron convienen en una mesma cosa, me pareció poner aquí la copia de una de ellas, aunque con alguna brebedad, por no repetir dos vezes difusamente un sucesso.

Se trata (pág. 111) de la "Copia de una carta escrita en el Cerco de Buda, luego que se dió el Assalto en el dia veynte y siete de Julio, de 1686". Según lo anotado por Kayserling, el texto de la página 110 añade el nombre del corresponsal, que Pizarro de Oliveros omitió en sus dos ediciones, pluralizándolo en "algunos particulares affectos, y interessados en los buenos sucessos" y "todas las cartas que vinieron ... copia de una de ellas». Quizás por no tener delante el libro de Pizarro de Oliveros, Kayserling no hace ninguna referencia al "Memorial" sobre la fidelidad política de los judíos, que Pizarro de Oliveros recoge en las páginas 183-195.

\section{LA FIDELIDAD JUdAICA EN ISAaC CARDoso}

Lo mismo que se reproducían copias de cartas llegadas desde Viena con las noticias del cerco, Pizarro de Oliveros dedica 12 páginas de su obra a reproducir, traduciendo del "alemán" al español, el "Memorial" de fidelidad que los judíos de Buda presentaron al general Schooning, cuyas tropas de vanguardia fueron las que entraron en el gueto. Las amistades judías de Pizarro de Oliveros, y quién sabe si algún donativo de Belmonte, contribuirían a esta inclusión in extenso. Pero como veremos más adelante, el documento que enseñaron a Pizarro de Oliveros no es más que un plagio abreviado de Isaac Cardoso.

Como es sabido, Fernando Cardoso, de familia conversa portuguesa, se estableció en Madrid, donde publicó varios libros y gozó de la estimación social de la corte. Sin embargo, su criptojudaísmo no pudo resistir más el disimulo y salió de España, estableciéndose en Venecia, en cuyo gueto vivió como judío público y tomó el nombre de Isaac ${ }^{11}$. Se estableció luego en

${ }^{11}$ Ha estudiado este cambio Yosef H. Yerushalmi en su De la Corte española el gueto italiano, Marranismo y judaismo en la España del siglo XVIr: El caso Isaac Cardoso, trad. M. y A. Cerezales (Madrid 1981). 
Verona, donde continuó su labor literaria. Después de su Philosophia Libera (Venecia 1673), en un giro intelectual, que ha analizado bien Enrique Rúspoli ${ }^{12}$, y siguiendo las huellas de Samuel Usque en portugués y de Yosef ha-Kohén en hebreo, publicó una historia de las persecuciones sufridas por los judíos a lo largo de la historia, poniendo siempre de relieve que, a pesar de ello, el pueblo de Israel sigue siendo el elegido de Dios para dar a conocer su unidad y sus preceptos. El libro se titula Excelencias de los Hebreos (Amsterdam 1679) y está dividido en dos partes. En la primera enumera las excelencias con que Dios ha beneficiado a los judíos. En la segunda, que tiene el título propio de Excelencias y Calunias de los Hebreos, enumera y rebate las calumnias que han tenido que sufrir por parte de sus envidiosos y enemigos. En el escrito de Cardoso se perciben las ideas corrientes en su época de nobleza y pureza de sangre, así como la aportación de "autoridades» mediante citas de los antiguos e incluso de escritores cristianos. Se remonta a los tiempos helenístico y romano, pasa al reino de Castilla y termina con la buena acogida que reciben en Italia y otros países. Siguiendo la costumbre de muchos judaizantes hispano-portugueses, cuando cita literalmente algún pasaje de la Biblia, sigue la versión "palabra por palabra" de la Biblia de Ferrara, fraseología que contrasta con el buen castellano que habitualmente emplea.

La "Sexta Calunia de los Hebreos. Infieles a los Príncipes" (págs. 367-377) comienza así:

La fidelidad ... no bastó para librarles de tan grave testimonio, siendo al contrario fidelissimos y leales por naturaleza, por Decreto Divino, y por agradecimiento, como lo provaremos con razones, y experiencia.

Por naturaleza son fieles siendo nobilissimos de sangre, y de antiguedad descendientes de aquellas tres luminarias ... Abraham, Yshac, Iahacob, y es la fidelidad compañera de la nobleza; observan con gran puntualidad los decretos y mandatos de los Principes en cuyas tierras assisten ... obedeciendolos con una lealtad exemplar.

Son fidelissimos à su Dios, siendo testigos perpetuos de su Unidad en vida, y en muerte, dexandose matar en varias tierras

12 "La trayectoria intelectual de Isaac Cardoso", en Los judaizantes en Europa y la literatura castellana del Siglo de Oro, ed. F. Díaz Esteban (Madrid 1994) págs. 335-339. 
por su Dios, y por su Ley, y por testigos de esa Unidad Santissima los escogió su Divina Magestad (Ysaias Cap. 44) Vos mis testigos si ay otro Dios afueras de mi ...

Por preceto divino son fidelissimos los Judios, pues les manda Dios, por su Profeta Yrmiahu que rueguen à Dios por la paz de la Ciudad, y Reyno donde viven (Yrmiahu Cap. 29) Requerid à paz de la ciudad, que hize captivar a vos alli, y orad por ella al Señor, que en su paz sera à vos paz. En las fiestas y pascuas echan la bendicion publicamente, à los Principes, y Republicas donde abitan, como tambien en la Pascua de Sucoth, ò Tabernaculos hazian sacrificios de los setenta toros por las setenta Naciones del mundo.

Por agradecimiento son tambien fieles ... El proverbio vulgar de los hebreos dize, hijos de Ysrael, hijos de Reyes ... Nace tambien la lealtad de los Judios de aquellas tres suyas propiedades naturales, que referimos en la quarta Excelencia caridad, piedad, y verguença, ò honestidad.

Conocieron bien esta fidelidad de los Judios los Reyes antiguos, tanto Griegos, como Romanos, y se servian dellos en negoce[i]os importantissimos como el grande Antioco Rey de Siria, que haviendo algunas sediciones, y rebueltas en sus Reynos de Frigia, y Lidia les embió allá dos mil familias de los Judios disponiendolos en los presidios, y fortalezas ...

\section{El «Memorial» del libro de Pizarro de Oliveros}

Aparte de su menor extensión, el alegato de fidelidad judía en Pizarro de Oliveros cambia en el modo de hablar. Cardoso, como historiador, habla de los judíos en tercera persona del plural («ellos»), mientras que aquí por ser un escrito que supuestamente han redactado los judíos de Buda, está en primera persona del plural («nosotros»). Esto obliga a ligeros cambios en el verbo. La necesidad de abreviar fuerza a cambios en las frases para hilvanar el discurso, a veces con trasposición en el orden de las frases y palabras y empleo de sinónimos que sustituyen a los originales. También era necesario evitar aquí cualquier expresión que pudiera disgustar a las cristianas autoridades imperiales; por esta razón, quizás, las citas bíblicas están en castellano normal.

La copia del "Memorial" con el alegato de fidelidad va precedido de la explicación de cómo se entregó (pág. 183) y seguido 
de la contestación recibida (págs. 195-196), que naturalmente no están en la obra de Cardoso, pero la secuencia de la argumentación y de los ejemplos sigue sus pasos.

En nuestra transcripción hemos señalado con letra cursiva las palabras tomadas literalmente de Cardoso. En ocasiones la ortografía o la acentuación pueden diferir en cada autor, cosa normal teniendo en cuenta la anarquía ortográfica de la época ${ }^{13}$.

Tras concluir con el asalto de Buda, que ha finalizado el día 2 de septiembre de 1686, continúa Pizarro de Olivares:

${ }^{183}$ Los Judíos se entraron por la Salva Guardia de el General Schooning, a quien tocó el Assalto por la parte de aquel Gueto, y proponiendole [exponiéndole] $\bar{q}$ su Nacion esparcida por las quatro partes de la Tierra, en todas las que se hallaban, eran siempre Leales à los Principes debaxo de cuyo Cetro vivian, le dieron un "Memorial" que contenia muchos exemplares [ejemplos], y algunas razones para confirmacion de esta propuesta. El qual traduzido de lengua Alemana en el Idioma Español, es como sigue

\section{EXCELENTISSIMO SEÑOR}

Los Judios que nos hallamos en esta Real ciudad de Buda, proponemos à Vuestra Excelencia que nuestra Nacion esparcida por las quatro partes de la Tierra, â sido siempre, y es no solo por razon natural, sino por precepto divino, muy Fiel, y Leal à todos los Principes en cuyas tierras assisten, porque como consta de el Capitulo veynte y nueve de Hieremias, nos manda Dios por este Propheta que roguemos en nuestras oraciones por ${ }^{184}$ la paz de la Ciudad, y Reyno en que vivimos, diziendo Requerid la $\mathrm{Paz}$ de la Ciudad en que os hize captivar, y orad por ella al Señor, que en su paz será para vosotros paz. Por esta causa se acostumbra en nuestras Sinagogas Bendecir en las Pasquas y en las Fiestas publicamente à los Principes, y à las Republicas en que habitamos, y en la Casa Sancta que lloramos arruinada en Hierusalem, sacrificabamos setenta Toros en la Pasqua de los Tabernaculos, por las setenta Naciones de el

\footnotetext{
${ }^{13}$ En cuanto al contenido, las páginas de Pizarro de Olivares se corresponden con las de Cardoso de la siguiente forma: 183/367, 184/367-368, 185/368-369, $186 / 369-370,187 / 370-371,188 / 371-372,189 / 372,190 / 372-373,191 / 373,192 / 373-$ 374-375, 193/375, 194/375-376, 195(175 por errata)/376-377. Indicamos el número de página mediante superíndice unido a la palabra (o parte de palabra) que la inicia; y entre corchetes insertamos algunas explicaciones léxicas y alguna variante especialmente significativa.
} 
Mundo. Observamos por lo mismo con gran puntualidad todos los Mandatos de los Principes, Reyes y Señores que nos admiten en sus tierras, no repugnandoles ni directa ni indirectamente su voluntad, Leyes, Pregmaticas, y Estatutos, sino obedeciendoles con una fidelissima lealtad, la qual conocieron muy bien los Reyes Antiguos, tanto Griegos como Romanos, pues se servian de los Judios en los negocios mas importantes à su Corona, el Gran Antioco Rey de Siria embió a los Reynos de Frigia, y de Lidia dos mil Familias de los Judios, para puestas y repartidas algunas personas de ellos en las Fortalezas, y Presidios evitasen las muchas Rebeliones de los Pueblos, y enfrenasen el orgullo de los perturbadores de la paz; assi lo ${ }^{185}$ escrevia Josepho en su libro de Bello Judoyco [sic], donde pone la carta que el Rey Antioco escrivió a su Capitan General Zeuxi; en la qual se deben notar entre otras muchas que hazen a nuestro proposito, aquellas palabras de el Rey: Que los Judios serian fieles guardias, y custodios vigilantes de sus cosas, porque servian a Dios piamente, y porque todos los antepassados Hebreos dan testimonio de su Feé, y buenos servicios. Seleuco Nicanor, en las Ciudades de Assia, y Siria, y en Antioquia su Metropoli, les dió à los Judios el derecho, y Privilegio de Ciudadanos, queriendo gozasen los mismos, que los Griegos, y Macedonios tenian. Los Alexandrinos, y Antioquenos, pidieron à Tito, y à Vespasiano, vencida ya Palestina, y Hierusalem, que rebocassen esta preheminencia, y derecho, y nunca lo pudieron conseguir, respondiendo aquellos Principes que ya havian castigado à todos los que tomaron Armas contra los Romanos, el qual castigo no se entendia contra los Judios, porque nunca pecaron, y assi que no seria justo privarlos de sus honras, y Privilegios. Grande Magnanimidad de estos Emperadores, que despues de tantas Guerras, Muertes, y Sediciones no consintieron obrar injustamente contra los Judios: y aun en su tiempo dize el ${ }^{186}$ citado Josepho, se les conservava aquella hidalguia. Levantandose los Jones contra los Judios, pidieron à Marco Agripa que si quisiessen habitar en la misma Ciudad que les havia dado Antioco Nieto de Seleuco, y gozar los Privilegios en ella, fuessen obligados los Judios à tributarles culto y adoracion à los propios Dioses que ellos veneravan, mas no les concedio Marco Agripa la demanda, antes ayudados los Judios del Patrocinio de Nicolao Damasceno, grande Historiador de aquellos tiempos, impetraron poder vivir segun su propia Ley, y Costumbres. Alexandro Magno, estando expugnando a Tiro, y haviendo yâ vencido en algunas ocasiones à los Capitanes de Dario, escrivio a los Judios pidiendoles dexassen la amistad de 
Dario, y que admitiessen la suya, à la qual respondió la fidelidad de los Judios, que devian guardarle lealtad a Dario hasta la muerte, porque estaban obligados con juramento à no tomar contra el las Armas. Aqui movió mucho mas à los Judios la Feé que le profesavan à Dario, que el peligro à que se exponian no haziendo la voluntad de Alexandro. Ptolomeo Sucesor de Alexandro en el Reyno de Egypto, confió la fortaleza de sus Exercitos à los Judios, y para Reynar seguro en Cirene, y en otras ${ }^{187}$ Ciudades de la Lidia [en Cardoso: Libia] embió à habitar à aquellas partes algunos de nuestra Nacion. Y el Rey Ptolomeo Filometor, y su Esposa Cleopatra, encomendaron todo el Reino à los Judios, y fueron sus Capitanes Onias, y Dositeo, los cuales siendo Hebreos, libraron de las rebelliones à aquella Corona, y asseguraron a Alexandria. Los Ptolomeas reyes de Egypto, para guarda de sus Personas, para los Prezidios de las Fortalezas, y para los mas importantes cargos escrive Josepho, se fiavan con la mayor satisfacion de los Judios. Estos socorrieron con mil y quinientos Soldados en la Guerra Alexandrina, à Julio Cesar, emperador romano, el qual les intituló gente Fiel, y grata al Romano Pueblo. Seyano Priuado de el Emperador Tiberio, intentando levantarse con el Romano Imperio, quiso desterrar de Roma à los Judios, por saber eran los que mas podian resistir a su pretension, y lo mismo parece que pensó Aman aquel gran Ministro de el Rey Assuero, el qual para poderse levantar con el Reyno de los Persas, viendo que Mardocheo no se le humillava, y que havia mostrado como buen Judio su fidelidad con el Rey, alcançó decreto Real para que muriessen todos los Judios de aquellos Reynos, y con su falta lograr el ${ }^{188}$ intento de su traidora ambicion.

En los tiempos Modernos, en los Reynos de Castilla, se fortificaron los Judios en la parte que les tocaba en la Ciudad de Burgos, contra el Rey Don Enrique que haviendo muerto al Rey Don Pedro su hermano, y señoreandosse de todos sus Reynos, aclamado de los Grandes, y Pueblos de España, pidió à los Judios que se le entregassen, à lo qual respondieron que ellos no conocian otro Señor, que al Rey Don Pedro, $o$ al que legitimamente le sucediesse: $y$ que por defender esta causa perderian todos resueltamente la vida. Estimó el Rey esta accion, y constancia de los Hebreos, diziendo que à tales Vassallos devian estimar mucho, y premiarlos los Reyes, porque apreciaban mas la fidelidad de un Rey vencido, y muerto, que la presente fortuna de el Vencedor. 
Estando los Judios en Alemania debaxo de el Emperador Carlos Quinto, y haviendo Martin Lutero con sus Dogmas rebuelto todo el Imperio, y la Iglesia, les pidió à los que vivian en Francaforte, una summa considerable de dinero, prometiendoles escrivir bien de ellos, y de su Religion, en su libro, à lo qual le respondieron los Judios que no lo podian hazer por la fidelidad que tenian, y devian à su Señor el Emperador, de lo qual se ${ }^{189}$ indignó tanto Lutero, que entre sus obras escrivió contra los Judios un libro con mil afrentas injurias y calumnias, hijas todas de su ira, y pasion, dando motivo con esto para que algunos de los Principes que siguen su Secta no los admitan en sus Tierras. En las Guerras de Alemania, del Bravo Gustavo Adolpho Rey de Suedia, defendieron valerosamente los Judios la Ciudad de Praga en Bohemia, en la parte que les tocaba, y fueron no pequeña para no ser presa la Ciudad, por lo qual obtuvieron grandes privilegios de el Emperador Ferdinando. En el decreto de los Reyes Catholicos, despachado en la Ciudad de Granada, à ultimo de el Mes de Março, de mil quatrocientos y noventa y dos, no consta que desterrassen à los Judios generalmente de España por ningun crimen de Lessa Magestad, ni por haver sido infieles à aquella Monarchia, sino porque les impusieron [imputaron] que inducian al Judaismo à muchos Christianos, principalmente à los Nobles de Andalucia. La Serenissima Republica da Venecia, experimentó muy bien la lealtad de los Judios en veynte y ocho años de Guerra que tubo en el Reyno de Candia contra el Turco, y de sus Historias consta el Amor con que la ayudaron, y los servicios grandes que la hizieron, ${ }^{190}$ por lo qual delante de muchos Gentiles Hombres que se lebantaron de sus entretenimiento para ver la Congrega de los Judios que por alli pasaba en un entierro, se lebantó uno de los mas graves, y quitandosse el Barrete, saludó cortesmente à todos los de nuestra Nacion, diziendo en altas bozes, $\hat{o}$ fidelissima Gente andad à vuestro Dios en paz.

Finalmente Señor. La traycion que nos imputa en las Coronicas de España el Arçobispo Don Rodrigo de que en los años de setecientos y catorze quando con su Capitan Tarif, entraron los Moros en aquellos Reynos, les entregamos la Ciudad, de Toledo abriendoles las puertas, no puede verificarse, porque aunque en la Historia que escrivio Don Lucas de Tuy, dize que los Christianos de Toledo confiados en la Fortaleza de la Ciudad sufrieron algun tiempo el sitio hasta que en el Domingo de Ramos saliendo todos en procession à un Iglesia de el Arrabal fuera de la Ciudad, entre tanto fueron recebidos por los Judios 
en ella los Turcos: contradize à todo esto Mariana Author desapasionado, y grave, el qual escriviendo la Historia de España, prueva que los mismos Ciudadanos por no poder resistir mas tan dilatado cerco, entregaron la Ciudad, con estas condiciones; que los que ${ }^{191}$ no quisiessen quedarse en ella, sacassen sus haziendas libremente, $y$ aquellos que gustassen vivir en la referida Ciudad, pudiessen seguir la Religion de sus Padres sin contradicion alguna, para lo qual se les havian de señalar siete Iglesias: que los Tributos fuessen los mismos que acostumbravan a pagar à los Reyes Godos, sin que los Turcos pudiessen honerarlos con otras imposiciones nuevas. Y finalmente, que se havian de governar por sus Leyes, y criar Juezes de su misma Nacion: conque segun lo historial de este Author se manifiesta que no se perdió Toledo por traycion que hizieron los Judios, sino por ser los cercados pocos en numero, $y$ por hallarse sin fuerças para poder resistir à tan poderoso Contrario. Tampoco haze contra nosotros lo que escrive Alonso de la Espina, en un Tratado contra los Judios, que trae en su libro intitulado, Fortalitium Fidei, en el qual refiere que un Medico de nuestra Nacion llamado Don Mehir, confessó haver muerto con veneno al Rey Enrique, y la razon es clara, porque no obstante que confirma el sucesso Garibay; Los que que escrivieron la Coronica de este Rey, y la de Don Juan el Segundo su hijo, que son Alvaro Garcia, Pedro Lopez de Ayala, Fernado Perez de Guzman, Marineo, Siculo, Vasco, y Ma ${ }^{192}$ riana authores todos gravissimos, no hazen mencion de tal cosa, y solo la imponen aquellos dos, por ser poco affectos à la Nacion Hebrea.

De todo lo referido, y de otras muchas particularidades que se podrian traer a nuestro proposito se concluye que los Judios son la misma Lealtad, y Fidelidad para los Principes que los admiten vivir en sus Tierras, y que por Precepto Divino, por su natural agradecimiento, y por las propiedades con que nacen no pueden obrar lo contrario. Es verdad que somos Peregrinos, y que nos esparció Dios en el Mundo por nuestros pecados; pero la ingratitud que tuvimos con la Magestad Divina, no es argumento forçoso para que la tengamos tambien con los hombres, siendo assi que la misma experiencia no lo muestra, la Ley que observamos nos lo prohibe, y el estudio de ella, nos enseña todas las virtudes Morales en que nos exercitamos, dando exemplo con ellas, y con nuestras Oraciones.

Bien lo conocieron los Antiguos Emperadores Romanos quando nos concedio Augusto, y Tiberio, nuestras Juntas y Sinagogas, viendo estos, y otros Monarchas que no sirven 
aquellas para excitàr novedades, sino para pedir pedir à Dios por la Paz Comun, y por el bien de los Reynos.

${ }^{193}$ Representamos finalmente à Vuestra Excelencia, que los Judios que oy viven esparcidos por el Mundo, no son verdaderamente Esclavos de los Principes en cuyos Reynos habitan, como pruevan claramente entre otros muchos, y muy graves Authores Teologos el padre Vasquez, y el Padre Marquez en su Governador Christiano, y si algunos dizen que son Esclavos los Hebreos se deve entender esta esclavitud en la forma que una Nacion entera puede servir, pero no siendo cada persona particular esclava de uno, y otro Señor. La mayor parte de los Judios que oy se hallan, no fueron conquistados en guerra justa, porque antes de la destruicion de Hierusalem por Tito Vespasiano, ya estavan repartidos por los Reynos, y Provincias de todo el Orbe, como afirman Strabon, Filon Judio, y otros Authores diziendo, que en el Templo segundo, ô por sediciones propias, ô por miedo de Tirano, ô por la Divina Providencia, ya estavamos divididos en muchas partes, siendo la causa principal de esta division, y esparcimiento el no haver seguido la Ley de Mosseh que Dios nos encomendó; y en ella está bien clara la Prophecia de estos castigos, porque aunque es cierto que Nabuchodonosor, y Vespasiano debellaron, y conquis ${ }^{194}$ taron la Tierra Sancta, y que Pompeyo fue el primero que la hizo tributaria, que razon, ô derecho tuvieron para esta conquista sino la soberbia, y ambicion de dilatar sus Monarchias? Dion Casio en su Historia Romana dize, que aunque à Tito, y à Vespasiano se les levantaron Arcos Triumphales, intitulandose Emperadores ninguno se llamó Rey de los Judios, siendo asi que era costumbre entre los Romanos atribuirse el Cognomen de las Provincias que conquistavan, como lo hizieron Scipion Africano, Metelo Cretense, Cesar Galico, y otros que se llamaron Germanico, Asiatico, Numidico \&ct. Mas ninguno se apellidó Rey Judayco, sin duda porque no permitió Dios mostrassen ser ellos los vencedores de aquella gente, sino meramente Ministros Executores de su Divina Justicia.

Sirven los Judios en las Tierras donde viven de utilidad, y acrescentamiento, porque como no las tienen, ni Reyno propio en que recogerse gastan en ellas todo lo que por su industria adquieren, sin conduzirlo à otras partes.

El Papa Cabeça de la Iglesia Catholica, permite en Roma d̀ $s u$ vista à los Hebreos, y les da licencia para que vivan, traten, y contraten en todo ${ }^{195}$ el Estado Eclesiastico; lo mismo los Emperadores de Alemania con ser defensores de la Iglesia. En Francia, en Yngalaterra, en Polonia, en Dinamarca, en Suedia, 
en Flandes, en Holanda, y en todas las Tierras de los Potentados de Ytalia, y en las Serenissimas Republicas de aquel País, assisten los Judios sin que se les ponga obstaculo à sus Leyes, Ritus, y Ceremonias: y lo mismo esperamos conseguir de la Cesarea Magestad de el Maximo Emperador LEOPOLDO en esta ciudad que oy â restaurado del Otomano Imperio, en cuya Grandeza, y Piedad confiamos que examinada nuestra Lealtad, y consideradas bien las razones que alegamos, nos ha de dar permisso de vivir con nuestras haziendas en ella; y guardarnos las mismas consideraciones que à todos los de Nuestra Nacion, permite en sus Tierras \&tc.

Despues de haver presentado el referido "Memorial" le dieron los Judios al dicho General Schooning, una cantidad de dinero, prometiendole mucha mas en adelante: el General respondió haria todo lo possible para favorecerlos, mas que como dependia toda la pretension de estos hombres de la Corte Cesarea, no podia el absoluta ${ }^{196}$ mente obrar sin la authoridad de su Magestad Imperial.

\section{CONClustón}

El otro historiador del asalto a Buda es Nicolás Oliver Fullana, Sargento Mayor de las tropas españolas en Flandes y cosmógrafo del rey de España. Era cristiano viejo, pero acabó judaizando y se casó con la escritora judaizante Isabel (Rebeca) Correa. Ambos eran amigos de Miguel de Barrios.

Oliver Fullana publicó primero una relación urgente con la noticia de la conquista de Buda, titulada Memorial Historico del Famoso Sitio, y Victoriosa Recuperación de Buda, Con succinto Diario de los Successos, y breve Narracion de las circunstancias. Presentado al Exmo. señor Don F. Antonio de Agurto ... Governador, y Capitan General de los Paises Baxos (Bruselas 1686, 12 págs.). En su opúsculo no se limita a la noticia del desarrollo del asalto y conquista de Buda por las tropas imperiales: explica además cómo había llegado la ciudad a poder de los Turcos y los nombres que tuvo antiguamente.

Un año después publicó además una obra general sobre Hungría: Recopilacion Historica de los Reyes, Guerra, Tumultos, y Rebeliones de Vngria, Desde su poblacion por los Hunnos, hasta el año presente, 1697 ... (Colonia 1687); en la última parte del libro (págs. 236-247) recoge, y a veces amplía, la información 
sobre la conquista de Buda dada previamente en su Recopilacion. Oliver Fullana pudo ser la fuente de muchos de los datos que utilizó Miguel de Barrios sobre Hungría y Buda. Sin embargo en ninguna de sus dos obras dice Oliver Fullana que los judíos de Buda entregaran un "Memorial" al general de las tropas imperiales ni hace la menor alusión a su existencia.

Tampoco habla de tal "Memorial» el periódico quincenal de Bruselas en español, Noticias Principales y Verdaderas, en las entregas desde el 17 de septiembre hasta diciembre de 1686.

Es posible, pues, que el "Memorial" que recoge Pizarro de Olivares y cuya existencia no puedo negar ni afirmar por falta de más información, fuera en realidad una traducción al alemán del texto castellano, ya que tal texto, como se ha visto, no es una traducción sino un plagio abreviado en castellano del capítulo sobre la fidelidad judía de Isaac Cardoso. ¿Lo hizo llegar a manos de los judíos de Buda el Conde Palatino don Manuel de Belmonte? El mote de su escudo era, precisamente, Virtute et Fide. La respuesta a esta duda es probable que se encuentre en los historiadores húngaros.

\section{APÉNDICES}

\section{Sobre la esclavitud DE los Judíos}

En el "Memorial" sobre la fidelidad de los judíos supuestamente entregado en Buda, que según se ha visto es un plagio abreviado de la "Sexta Calumnia" de Isaac Cardoso, se hace referencia a si los judíos eran o no esclavos de los soberanos en cuyas tierras viven. Pizarro de Oliveros copia a Isaac Cardoso y a los autores que éste aduce: "muy graves Authores Teologos, el Padre Vasquez y el Padre Marquez en su Governador Christiano". Se comprende que para los judíos esta cuestión era de la mayor importancia, pero también para los cristianos planteaba dudas legales y teológicas que los escolásticos de los siglos XVI y XVII tenían que solucionar.

Durante la Edad Media los judíos eran, como suelen repetir los documentos, "de la cámara del rey" o "el tesoro del rey". Esta dependencia directa del rey les salvaba de muchas tropelías locales. El problema que se plantean ahora los juristas y 
teólogos es el de si tal dependencia constituía una esclavitud o no. O de forma más personal, si los judíos son o no esclavos. La solución se buscaba en el relato bíblico de cuando el Faraón ordenó los trabajos forzosos de los hebreos para hacer adobes. Cardoso (pág. 375) lo expone así:

Y que los Judios que oy viven no son verdaderamente esclavos de los Principes en cuyas tierras habitan lo pruevan claramente graves Autores, Theologos, como Vazquez, y Marquez en su Governador Christiano, y si algunos Autores dizen que son esclavos se entiende en la forma que una Nacion entera puede servir, no siendo cada persona esclava de uno, y otro Señor, mas toda ella sugeta, y detenida contra su voluntad debaxo de un Imperio desigual con los otros Ciudadanos. En la servidumbre de Egypto la Sagrada escritura una vez los llama siervos, otra vez peregrinos, y aun en aquella cautividad no servia un particular Judio à otro Egypcio estando debaxo de su mera disposicion sin mas libertad ni mas autoridad sobre sus bienes, que las que le permite el amo, ni el Rey les tomo los bienes, y haziendas, sino que los afligia con insoportables vexaciones.

La mayoría de las frases de Cardoso incluida la referencia a Velázquez, están tomadas del libro de Juan Márquez,

El Governador Christiano Deducido De Las Vidas de Moysen y Josve, Principes del Pueblo de Dios. Por el Maestro F. Ivan Marqvez, de la Orden de San Agustin, Cathedratico de Visperas de Theologia de la Vniversidad de Salamanca. Dirigido a Don Gomez Svarez de Figuerroa y Cordoua, Duque de Feria ... Con Quatro Tablas muy curiosas La primera de los Capitulos: la segunda de las Questiones: la tercera de las cosas notables: y la quarta de los lugares de Escritura. Con Privilegio de Castilla y Aragon. Con Licencia. En Pamplona, por Carlos Labàyen, Año de M.DC.XV.

Está impreso en dos gruesos tomos in folio, de agradable lectura, y responde a la petición del difunto duque de Feria, padre del dedicado, de que se le aconsejara sobre qué debe hacer un gobernante cristiano que tiene a veces que actuar con escrúpulos de conciencia. El padre Juan Márquez quiere establecer un equilibrio (prólogo "Al Letor"):

Siempre me ha parecido la mayor dificultad del gouierno Christiano, el encuentro de los medios humanos con la ley de 
Dios; porque si se echasse mano de todos, se auenturaria la conciencia; y si de ninguno, peligrarian los fines, en detrimento del bien comun ... nunca aproué a los que forman escrupulos con poco fundamento;

es natural, por tanto, que recomiende a veces manga ancha con las debilidades ajenas, pues «no conservara Dios en el mundo sin grandes cosas los pecadores: y que es parte necessaria del gouierno saber permitir» (cap. VIII, pág. 235).

El libro se publicó en Salamanca por primera vez en 1612 , se reeditó en Pamplona en 1615 (edición por la que se cita), y luego en Madrid 1625, 1629, 1640, 1652, 1664 y 1773; en Alcalá de Henares 1634; en Amberes y Bruselas 1664. A lo largo del siglo XVII, como lo prueba la cita de Cardoso y las varias ediciones, la obra del padre Márquez gozó de difusión y prestigio.

Dentro del buen gobierno está el trato y la licitud de la esclavitud (cap. II, pág. 13):

no padece duda que en la Republica Christiana se puede permitir esclauos, ni que deuen atender las de buen gouierno, a que el numero dellos no crezca demasidamente: porque siendo excesiua la cātidad ella mismo prouoca el alboroto.

La esclavitud sólo puede ser lícita si es el enemigo vencido en una guerra justa al que se le ha perdonado la vida.

Sobre la esclavitud de los judíos, que Cardoso -y su plagiario del "Memorial»- copia literalmente, dice Márquez (cap. II, pág. 8):

en la forma de la afliccion les dexaron la libertad necesaria, para que digamos que siempre quedaron aduenas [advenedizos, extranjeros], y peregrinos, y que esclauos en todo rigor no lo fueron. Porque lo primero priuadamente no servian a nadie, y entre ellos cabeças de familias con la patria potestad de disponer de sus hijos ... Tenian juezes de su mesma nacion ... Faraon no tocò en las haziendas de los Hebreos, antes se las dexò en la mesma disposicion que las gozauan en el tiempo de su libertad, ni aun les cargò muchos tributos ... el intento que tuuo el Rey en oprimir este pueblo no fue enriquezer[se] à su costa ... sino assegurarse del ... por lo mucho que auia crecido ... Digo pues, que auiendo sido injusta la cautividad por la potencia y tirania del Rey de Egypto, la seruidumbre no lo fue de derecho, pero que lo fue de hecho en todo rigor, y propiedad, como dan a entender las diuinas Letras, aunque no de la manera que 
vn hōbre particular se haze sieruo, o esclauo de otro, estādo debaxo de su mera disposiciō, sin mas libertad, ni autoridad sobre sus bienes, y acciones $\bar{q}$ las $\bar{q}$ le permite el amo, sino en Ia forma que vna nacion entera puede seruir, no siēdo cada persona esclauo de uno, ni otro señor, mas estando toda ella sugeta, y detenida cōtra su voluntad debaxo de un imperio desigual cō los otros Ciudadanos de la Republica, en que habitan ... En esta razon es verisimil, que se fundaron los Teologos Escolasti$\cos$, que sintieron que los Judios que oy viuen son verdaderamente esclauos, y sieruos de los principes, en cuyas tierras tienen su habitacion: si bien es sentencia que se reprueua comunmēte, y parece cōtra la costūbre de la Iglesia, que si los tuuiera por esclauos no dexara de bautizarles los hijos pequeños cötra su voluntad; pero dexalo de hazer por no ir contra los derechos de la patria potestad, como un graue autor de esta edad ha notado curiosamente: cierta señal de los tiene por libres. (Vazquez. Tō. 2. in 3. part. disp. 155. cap. 5).

El citado Vázquez es el escolástico jesuita Gabriel Vázquez, quien comenta las Sumas de Santo Tomás de Aquino en cuatro gruesos volúmenes in folio. La cita que hace Márquez se refiere al comentario a la suma tercera (en dos tomos):

Gabrielis Vazquez Bellemontani Theologi celeberrimi è Societate IESV Commentarii ac Disputationes In Tertiam Partem Svmmae Theologiae Sancti Tomae Aquinatis: Qvibus non solvm versvm, et Germanvm Intelectvm sententiae ... explanat; Sed eam quoque tum Sacrae Scripturae Auctoritate, tum etiam SS. Patrum ... Venetiis Apud Iuntas, MDCX.

Sólo he tenido acceso al tomo primero de esta obra, impresa en Venecia en 1610, de modo que no he podido comprobar la referencia al tomo segundo. Sin embargo, las ideas del padre Vázquez se pueden ver en su otra obra (también en dos tomos), en la que comenta la parte primera de la segunda suma:

Commentariorum, Ac Dispvtationvm in Primam Secundae $S$. Thomae. Tomvs Secvndvs. Avthore Patre Gabriele Vazquez Bellmontano, Theologo Societatis IESV. Additum Est In fine Integrvm exemplar Concilij Palestini. Ad Illustrissimum D. D. Franciscum Gomezium de Sandoval, \& Roxas, Ducem de Lerma ... Anno 1605 Cvm Privilegio. Compluti, Ex Officina Iusti Sanchez Crespo.

La primera edición es de Alcalá de Henares 1599, la segunda es ésta de 1605, y también volvió a ver la luz en Alcalá en 1613 
y 1615; fuera de España hay ediciones en Ingolstad 1612 y en Lyon 1620. Se trata por tanto de una obra muy estimada y difundida, y que para los lectores de Juan Márquez bastaba con la indicación «Vazquez. Tō. 2. in 3. part. disp. 155. cap. 5».

El libro de Vázquez está estructurado en "cuestiones» y «disputas" numeradas, y las diversas materias que se encuentran en cada una de ellas llevan un número al margen, lo que permite su localización desde un índice.

Sobre la licitud de la servidumbre o esclavitud, afirma que no está prohibida por la ley natural y pertenece al derecho de gentes (Disputatio 157, n. 27,18 ss) y que por ello al siervo no le está permitido huir, salvo que se vaya a su patria, en cuyo caso ya no queda bajo el dominio de otro. Todos los autores ven al esclavo lícito como al vencido en una guerra justa que se le perdona la vida.

El padre Vázquez es la inspiración del padre Márquez, a quien copia Isaac Cardoso y éste a su vez es copiado por el autor del "Memorial».

\section{LA CONVERSIÓN SIMULADA}

La licitud o ilicitud de la conversión religiosa simulada es otro de los temas tratados por Gabriel Vázquez en sus Comentariorvm, y conocer su opinión en esta materia pudiera tener cierto interés, porque a lo largo del "Memorial», es decir, en el plagio resumido de las Excelencias y Calunias de los Hebreos de Isaac Cardoso, se insiste en que los judíos son "testigos perpetuos de su Unidad en vida, y en muerte, dexandose matar en varias tierras por su Dios, y por su Ley».

Es evidente que la realidad histórica del marranismo, o facilidad de los judaizantes hispano-portugueses para mantener una convivencia personal, que yo creo sincera, de un exterior cristiano y un interior judío empaña, cuando menos, tan apologética afirmación. En otro lugar ${ }^{14}$ expuse mi opinión de que la influencia del "disimulo" musulmán sobre Maimónides, y la de éste sobre el judaísmo español pudieran explicar la frecuencia de la conversión simulada entre los judíos ibéricos.

\footnotetext{
${ }^{14}$ Véase mi artículo "La expulsión y la justificación de la conversión simulada», Sefarad 56 (1996) págs. 251-264.
} 
Por otra parte, el marranismo del siglo XVI y del XVII es un fenómeno en cierto modo ajeno a los judíos españoles y se debe sobre todo a los judíos portugueses.

En 1492 los judíos de Castilla y Aragón tuvieron al menos la oportunidad de seguir siendo judíos marchándose del país en un plazo de tres meses; los que se quedaron, o eran acomodaticios o habían decidido intentar convencerse de que podían integrarse en la sociedad cristiana. En Portugal, en 1497 no tuvieron esa oportunidad: todos fueron bautizados a la fuerza. Estos nuevos cristianos portugueses difícilmente podían ser cristianos sinceros. Los que han estudiado su creciente venida a España durante la unión de las Coronas de España y Portugal y su incorporación numerosa a la sociedad española no han reparado en los dos diferentes tipos de conversos que convivían en Madrid y otras ciudades españolas.

Los descendientes de los conversos de Castilla y Aragón normalmente no tendrían un criptojudaísmo tan "urgente" o pugnaz como los de Portugal, que añadían además la indignación de la violencia sufrida.

No deja de ser curioso el que casi todos los grandes escritores judaizantes sean o procedan de Portugal, mientras que los españoles de origen judío produjeran santos (santa Teresa de Jesús) o humanistas cristianos (Luis Vives).

La justificación del disimulo tiene todavía en Immanuel Aboab una tenue defensa. En su Nomologia o discursos Legales Compuestos por el virtuoso Haham Rabi Imanuel Aboab de buena memoria. Estampado a costa, y despeza de sus herederos, en el año de la creacion 5389, publicado en 1629 pero terminado en 1625, trata (cap. 14 fol. 66) de "quando, y por quales ocasiones, deua, o sea obligado ... morir por la santificación de su sancto nombre: y quando es obligado (aunque sea passando la ley) á vivir». La idolatría, el homicidio y la deshonestidad obligan a aceptar la muerte, pero fuera de estas tres, en las otras transgresiones (sábado, etc.), si el soberano tirano lo hace para su provecho y no por religión, se puede transgredir la Ley si hay menos de diez testigos.

El padre Vázquez en su Commentariorum es taxativo: «Ex nullo capite licet simulare falsam religionem" (Disputatio 182, $\mathrm{n}$. 35 y ss., págs. 476-477). A pesar de las severas censuras de I. 
Aboab, los marranos o judaizantes hispano-portugueses de los siglos XVI y XVII no hicieron mucho caso de ellas.

\section{RESUMEN}

Tras la recuperación cristiana de la ciudad en 1686 , los judíos del gueto de Buda(-Pest) presentaron un "Memorial" manifestando su deseo de seguir viviendo allí y exponiendo la fidelidad de los judíos a los soberanos de los países donde habitan. El texto que recoge el historiador Pizarro de Oliveros (1687) es un plagio resumido de la calumnia sexta del libro de I. Cardoso Las Excelencias de los Hebreos (1679), y no es una traducción de un original alemán.

\section{SUMMARY}

After control of the city of Budapest was wrested from the Turks by Christian armies in 1686, the Jews of the Budapest ghetto presented a Memorial to their new monarchs pledging allegiance and expressing their desire to remain in Hungary. The text of the Memorial, which was reproduced by the historian Pizarro de Oliveros (1687), is nothing other than an abbreviated plagiarism of the sixth in the series of slanderous propositions that Isaac Cardoso includes in his Las Excelencias de los Hebreos (1679). It is not a translation from a German-language original. 